\title{
Preterm infant feeding performance at term equivalent age differs from that of full-term infants
}

\author{
Roberta Pineda $\mathbb{( I )}^{1,2,3} \cdot$ Danielle Prince ${ }^{1} \cdot$ Jenny Reynolds ${ }^{4} \cdot$ Molly Grabill $^{1} \cdot$ Joan Smith $^{5}$
}

Received: 4 November 2019 / Revised: 21 January 2020 / Accepted: 4 February 2020 / Published online: 17 February 2020

(c) The Author(s), under exclusive licence to Springer Nature America, Inc. 2020

\begin{abstract}
Objective To identify differences in feeding skill performance among preterm infants at term equivalent age compared with full-term infants.

Study design Ninety-two infants ( 44 preterm infants born $\leq 32$ weeks gestation at term equivalent age and 48 full-term infants within 4 days of birth) had a standardized oral feeding assessment.

Result Preterm infants at term equivalent age had lower Neonatal Eating Outcome Assessment scores (67.8 \pm 13.6 compared with $82.2 \pm 8.1 ; p<0.001)$ and were more likely to have poor arousal $(p=0.04)$, poor tongue positioning $(p=0.04)$, suck-swallow-breathe discoordination $(p<0.001)$, inadequate sucking bursts $(p=0.01)$, tonal abnormalities $(p<0.001)$, discoordination of the jaw and tongue during sucking $(p<0.001)$, lack of positive engagement with the feeder and/or discomfort $(p<0.001)$, signs of aspiration $(p<0.001)$, difficulty regulating breathing $(p<0.001)$, and have an inability to maintain an appropriate state $(p<0.001)$, and complete the feeding $(<0.001)$.

Conclusion A broad range of feeding-related difficulties appear to remain evident in preterm infants at term equivalent age.
\end{abstract}

\section{Introduction}

An estimated $80 \%$ of premature infants will experience difficulty with oral feeding during neonatal intensive care unit (NICU) hospitalization [1-3]. Feeding difficulties can result from central nervous system immaturity [3-5], medical complications [6], and/or cerebral injury [7, 8]. Immaturity can result in inadequate readiness cues, poor state regulation, and poor oral motor reflexes that support

$\triangle$ Roberta Pineda

pineda_r@kids.wustl.edu

1 Program in Occupational Therapy, Washington University School of Medicine, St. Louis, MO, USA

2 Department of Pediatrics, Washington University School of Medicine, St. Louis, MO, USA

3 University of Southern California, Chan Division of Occupational Science and Occupational Therapy, Keck School of MedicinePediatrics, California, USA

4 Baylor University Hospital, Division of Baylor Scott \& White Rehabilitation Hospital, Dallas, TX, USA

5 Department of Quality, Safety, and Practice Excellence, Saint Louis Children's Hospital, St. Louis, MO, USA feeding [4], but most infants will progress to full oral feedings prior to or close to term equivalent age (38-40 weeks postmenstrual age (PMA)) [9, 10]. While many preterm infants are able to achieve full oral feedings prior to NICU discharge, many continue to have feeding challenges at term equivalent age [11].

In the NICU, the introduction of oral feeding occurs when the infant demonstrates signs of oral feeding readiness, which typically occurs around 34 weeks PMA [12]. During this time of early oral feedings, preterm infant feedings are frequently characterized by an inability to maintain an appropriate state for feeding, discoordination of sucking, and inadequate organization of the suck-swallow-breathe pattern $[1,2,4,5,12]$. Feeding may also be further complicated by physiological instability of the infant, with bradycardic and desaturation events, which have been associated with an increased risk of aspiration during feeding [9, 13]. These early feeding challenges can result in an extended stay in the NICU [14-17].

Oral feeding in preterm infants improves as they approach term equivalent age [10]. Specifically, behavioral responses needed for successful oral feeding, coordination of the sucking pattern, and protection of the airway during swallow improve in a linear fashion with maturity [18]. Studies have demonstrated differences in suck-swallow-breathe 
coordination [19], oral tone [15], and sucking efficiency among preterm infants and full-term infants [14, 20]. Capilouto and colleagues were able to demonstrate differences in preterm and full-term infants' feeding using a technology that quantifies nutritive sucking. They observed that preterm infants have higher suck frequency, with shorter suck duration, and less sucking smoothness [21]. However, no studies that we are aware of have defined differences in oral feeding performance, along with differences in specific types of feeding-related behaviors, among full-term infants compared with preterm infants at term equivalent age using standardized feeding assessments of a typical oral feeding in the NICU. Understanding if differences exist, and what aspects of feeding differ, can improve our understanding of feeding challenges that continue to exist among preterm infants at term and enable targeted interventions to optimize outcome.

\section{Study design}

This study was approved by the Human Research Protection Office at Washington University in St. Louis, and the infant's mother provided written informed consent.

One hundred and one infants were prospectively enrolled (50 preterm infants and 51 full-term infants) and had feeding assessed using the Neonatal Eating Outcome Assessment [22]. Feeding performance, as well as different types of feeding behaviors represented on the standardized feeding assessment were compared between the preterm and full-term groups.

\section{Preterm infants}

Fifty preterm infants born $\leq 32$ weeks estimated gestational age (EGA) were prospectively enrolled prior to oral feeding initiation from January 2015 to June 2015 as part of an overarching study investigating feeding progression across PMA. Infants were excluded if they had a congenital anomaly or were born $>32$ weeks EGA. All congenital anomalies were excluded including conditions such as Trisomy 21, VACTERL sequence, cardiac anomalies, and cleft lip and palate. Infants were recruited from the 85-bed level IV NICU at St. Louis Children's Hospital in St. Louis, Missouri. At term equivalent age (between 35 and 43 weeks PMA), after the infant had achieved full oral feeding and NICU discharge was being planned, an oral feeding was video recorded and scored with the Neonatal Eating Outcome Assessment. Full oral feeding was defined on the infant having full oral intake of their nutritional volume for at least $24 \mathrm{~h}$. For the assessment, each feeder was instructed to feed the infant as they normally would. At the study site, infants were fed by their parents when they were present, and the mode of feeding (breast or bottle) was at their discretion. When parents were unavailable, infants were most often fed by a member of the nursing staff, an occupational therapist, or speech-language pathologist by bottle.

\section{Full-term infants}

Fifty-one consecutive admissions of full-term infants born $>37$ weeks EGA were enrolled within the first $48 \mathrm{~h}$ of life from May 2016 to August 2016. Infants were excluded if they had a congenital anomaly, cerebral injury, intensive care stay, if they were born $<37$ weeks EGA, or had parents who were non-English speakers. Infants were recruited from the 35-bed labor and delivery floor at Barnes-Jewish Hospital in St. Louis, Missouri. An oral feeding assessment was performed within 4 days of birth, prior to discharge from the hospital. Parents were instructed to feed their infant as they normally would, and the feeding was video recorded and scored with the Neonatal Eating Outcome Assessment. The mode of feeding (breast or bottle) was at the parent's discretion.

\section{Medical and demographic factors}

The following information was collected from the medical record: maternal age, maternal marital status, insurance type (public or private), infant sex, and infant race (African-American or non-African-American). Infant medical factors collected included the presence of cerebral injury [defined as presence of cystic periventricular leukomalacia or grade III-IV intraventricular hemorrhage (IVH) from MRI or cranial ultrasound], necrotizing enterocolitis (NEC; all stages), and chronic lung disease (requiring supplemental oxygen at 36 weeks PMA or requiring at least 28 days on $>21 \%$ oxygen). The number of days on supplemental oxygen, continuous positive airway pressure, mechanical ventilation, and total parenteral nutrition were also documented. Finally, the EGA at birth (based on dates or Ballard exam, when dates could not be determined with accuracy) and length of stay in the hospital after birth were documented.

\section{Neonatal Eating Outcome Assessment}

The Neonatal Eating Outcome Assessment is a standardized tool used to assess feeding skills in infants prior to and at term equivalent age and includes 18 scored feeding items [23]. The Neonatal Eating Outcome Assessment has good to excellent inter-rater reliability and has concurrent validity with relationships to the Neonatal Oral Motor Assessment Scale [22, 24].

The Neonatal Eating Outcome Assessment has three scored sections, (prefeeding behaviors, oral feeding, and 
observations at the end of feeding). There are six items related to oral motor skills assessed prior to initiation of oral feeding, nine items assessed during oral feeding, and three items related to observations made at the end of the feeding. Each item receives a letter score, derived from specific standardized criteria outlined in the manual. Scores for each item adjust based on expected performance for each PMA, with the letter score being converted to either 1,3 , or 5 points. A score of 1 on an item reflects a feeding challenge (abnormal) for that PMA, a score of 3 reflects a questionable performance (emerging, immature response, or feeding challenge), and a score of 5 reflects a normal performance. Each item score is then summed for a total raw score. Raw scores can range from 18 to 90, with higher scores indicating better oral feeding performance. Raw scores can then be categorized as normal (77-90), questionable (58-76), or feeding challenged (18-57), based on established ranges.

In addition to investigating total feeding assessment scores, various aspects of oral feeding were captured from specific items on the Neonatal Eating Outcome Assessment including: I-1 arousal, I-4 rooting and grasp, I-5 initiation of sucking, I-6 tongue, I-7 nonnutritive sucking, II-1 suck-swallow-breathe coordination, II-2 sucking burst length, II-3 suction, II-4 oral tone, II-5 quality of sucking movements, II-6 behavioral response to feeding, II-7 fluid loss, II-8 swallow, III-1 feeding completion, and III-2 state maintenance. Because of the variety of potential feeding behavior manifestations, the items from the assessment were recoded and grouped to ensure optimal exploration of infant feeding capabilities during statistical analysis. See Table 1 for information on how each feeding construct was recoded to define poor arousal, poor rooting and grasp, lack of sucking initiation, poor tongue positioning, suck-swallow-breathe discoordination, inadequate sucking bursts, inadequate suction, tonal abnormalities, discoordination of the jaw and tongue during sucking, lack of positive engagement and/or discomfort during feeding, moderate to severe fluid loss, signs of aspiration, difficulty regulating breathing, inability to finish feeding, and inability to maintain an appropriate state for feeding.

Each video recorded feeding was assessed by a single evaluator, who had been trained by the author of the assessment and underwent testing to ensure reliability. Videotapes were not blinded as it was apparent which infants were in the NICU and which were on the labor and delivery floor.

\section{Statistical analysis}

Statistical analyses were conducted using IBM's Statistical Package for the Social Sciences version 24.0 IBM Corp., Armonk, N.Y., USA. Independent samples $t$-tests were used to determine differences in Neonatal Eating Outcome Assessment scores among the preterm and full-term infants. Chi-squared analyses and Fisher's exact tests were used to determine differences between the preterm and full-term infants on each of 15 recoded feeding behaviors from the Neonatal Eating Outcome Assessment. Significance was defined as $p<0.05$.

\section{Result}

One hundred and one infants (50 preterm and 51 full-term) were enrolled. One full-term infant was later excluded due to an identified congenital anomaly. Due to the lack of feeding readiness at the time of assessment, feeding assessments were not obtained on 8 infants ( 6 preterm and 2 full-term infants), leaving 92 infants ( 44 preterm infants and 48 full-term infants) for analysis. The mean PMA when the feeding assessment was administered did not differ significantly between preterm and full-term infants $(38.1 \pm 2.6$ in the preterm group, compared with $38.7 \pm 1.0$ in the fullterm group; $p=0.17$ ). There were more infants who were bottle-fed in the preterm group $(43 ; 98 \%)$ compared with the full-term group $(23 ; 50 \%) ; p<0.001$.

Table 2 identifies infant medical and maternal characteristics for each group.

\section{Differences in feeding performance among preterm and full-term infants}

Table 3 displays the differences in feeding performance between preterm infants at term equivalent age and full-term infants. Preterm infants had significantly lower scores on the Neonatal Eating Outcome Assessment [67.8 \pm 13.6 (which is considered "questionable"), compared with $82.2 \pm 8.1$ (which is considered normal) among full-term infants; $(p<0.001)]$. More full-term infants $(n=37 ; 77 \%)$ received "normal" scores, compared with preterm infants $(n=11 ; 25 \% ; p<0.001)$. Fewer full-term infants $(n=1$; $2 \%$ ) had a "feeding challenge," compared with preterm infants $(n=11 ; 25 \% ; p<0.001)$. There were also fewer "questionable" feeders in the full-term group $(n=10 ; 21 \%)$, compared with preterm group $(n=22 ; 50 \% ; p<0.001)$.

\section{Differences in specific feeding behaviors among preterm and full-term infants}

Refer to Table 3 for differences in each feeding construct among preterm and full-term infants. We reran the analyses excluding infants $<38$ weeks PMA at the time of testing, and the findings remained largely unchanged. We reran the analyses excluding infants with cerebral injury and NEC, and the findings remained largely unchanged. 


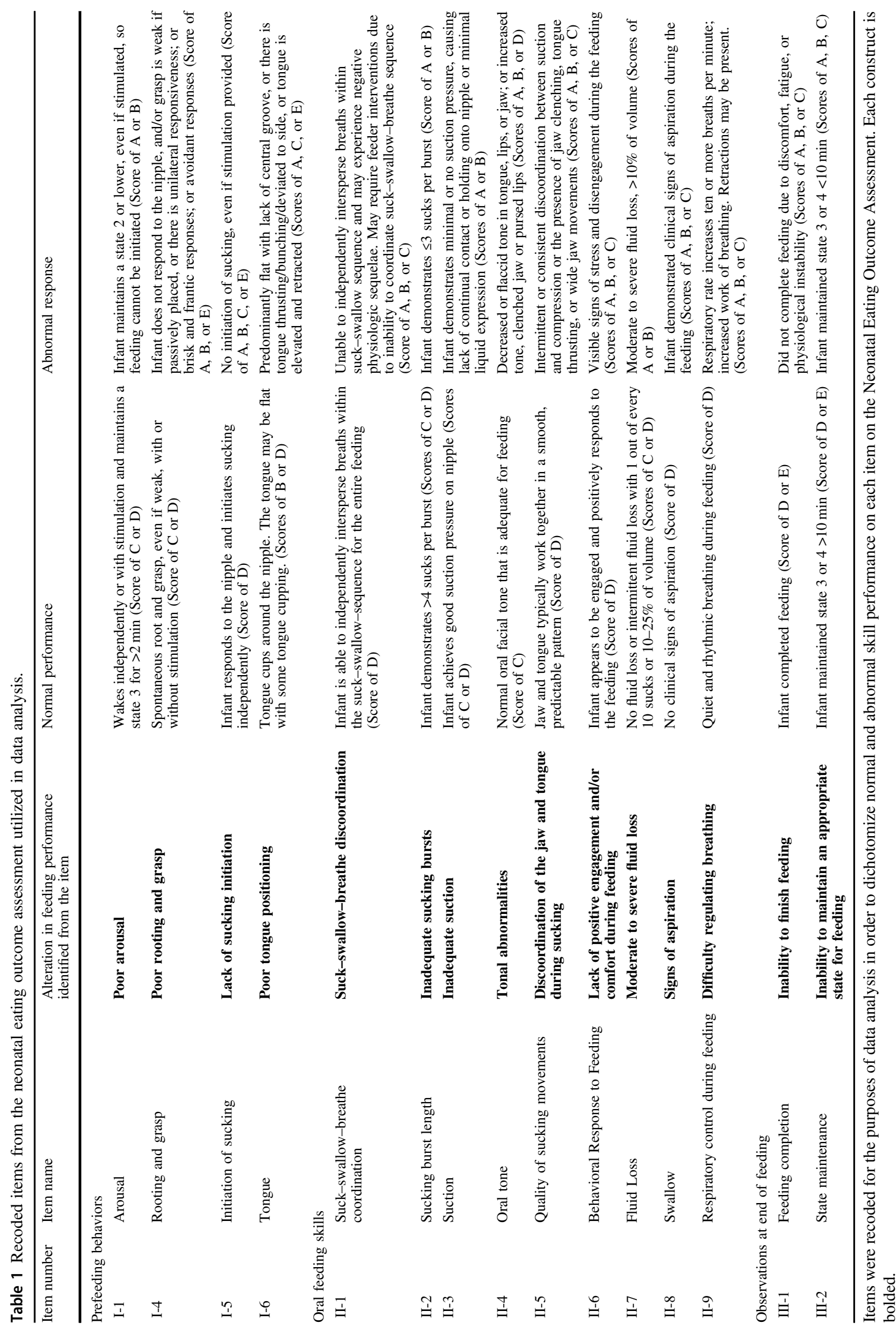


Table 2 Maternal and infant characteristics of the cohort.

\begin{tabular}{|c|c|c|c|c|}
\hline & \multicolumn{3}{|c|}{ Mean $\pm \mathrm{SD}$ or $N(\%)$ or median (IQR) } & \multirow[t]{2}{*}{$* p$ value } \\
\hline & $\begin{array}{l}\text { Total sample } \\
(n=92)\end{array}$ & $\begin{array}{l}\text { Preterm } \\
(n=44)\end{array}$ & $\begin{array}{l}\text { Full-term } \\
(n=48)\end{array}$ & \\
\hline \multicolumn{5}{|l|}{ Maternal factors } \\
\hline Maternal age & $27.9 \pm 6.5$ & $28.5 \pm 7$ & $27.6 \pm 6$ & 0.51 \\
\hline Maternal marital status: single & $28(30 \%)$ & $17(39 \%)$ & $11(23 \%)$ & 0.11 \\
\hline Race: African-American & $53(58 \%)$ & $18(41 \%)$ & $35(73 \%)$ & 0.003 \\
\hline $\begin{array}{l}\text { Mode of delivery: } \\
\text { Caesarean section }\end{array}$ & $44(48 \%)$ & $28(64 \%)$ & $16(33 \%)$ & 0.001 \\
\hline Insurance type: public & $61(66 \%)$ & $27(61 \%)$ & $34(70 \%)$ & 0.748 \\
\hline \multicolumn{5}{|l|}{ Infant factors } \\
\hline Infant sex: female & $50(54 \%)$ & $22(50 \%)$ & $28(58 \%)$ & 0.42 \\
\hline EGA (weeks) & $33.4 \pm 5.8$ & $\begin{array}{l}27.7 \pm 2.6 \\
\text { (range 23-32) }\end{array}$ & $\begin{array}{l}38.6 \pm 1 \\
(\text { range } 37-41)\end{array}$ & $<0.001$ \\
\hline LOS (days) & $41.5 \pm 9$ & $85.1 \pm 39.7$ & $3.4 \pm 1$ & $<0.001$ \\
\hline Days on ventilator & & $1(0.3-13.8)$ & & \\
\hline Days on CPAP & & $0(0-1)$ & & \\
\hline Days of nasal cannula & & $27(6.5-41.5)$ & & \\
\hline $\begin{array}{l}\text { Supplemental oxygen during } \\
\text { feeding assessment: yes }\end{array}$ & & $12(27 \%)$ & & \\
\hline Days on TPN & & $10.5(6.3-16)$ & & \\
\hline Chronic lung disease & & $34(77 \%)$ & & \\
\hline NEC & & $4(9 \%)$ & & \\
\hline Cerebral injury (PVL or IVH) & & $7(16 \%)$ & & \\
\hline
\end{tabular}

EGA Estimated gestational age, TPN total parenteral nutrition, $L O S$ length of stay, NEC necrotizing enterocolitis, $P V L$ periventricular leukomalacia, $I V H$ intraventricular hemorrhage, $C P A P$ continuous positive airway pressure.

Bold values are those that reached significance $(p<0.05)$, indicating a difference in the preterm and full term groups.

* $p$ value is from investigations of differences in maternal and infant factors across the preterm and full-term groups using independent sample $t$ tests for continuous variables and chi-squared analyses for categorical variables.

\section{Discussion}

The key findings of this study are that preterm infants at term equivalent age continue to experience difficulty with oral feeding performance. Their feeding behaviors differ from their full-term counterparts, with poor arousal, poor tongue positioning, suck-swallow-breathe discoordination, inadequate sucking bursts, tonal abnormalities, discoordination of the jaw and tongue during sucking, lack of positive engagement or discomfort, signs of aspiration, difficulty regulating breathing, and inability to maintain an appropriate state and complete the feeding. By identifying specific alterations in the feeding performance of preterm infants, targeted interventions can be developed, implemented, and tested.

Our findings of lower scores on standardized feeding assessments in preterm infants at term equivalent age are consistent with other reports. Eleven $(25 \%)$ preterm infants were identified to have a "feeding challenge," and $22(50 \%)$ had "questionable" feeding performance. Other reports of feeding problems in preterm infants at term equivalent age report a prevalence between $20 \%$ and $40 \%$ [25-27]. These high rates of feeding alterations are not observed among infants born full-term $[14,15]$.

It is well-understood that arousal increases across PMA $[28,29]$, yet it is not well-understood when and if preterm infants demonstrate the same level of arousal as their fullterm counterparts by the time they reach term equivalent age. Observations of lower arousal during periods of immaturity have led to a model of care in the NICU that allows the infant to demonstrate readiness cues to indicate they are ready for oral feeding, with arousal being one of the precursors [30, 31]. Although infants that are born preterm frequently struggle to maintain an appropriate level of arousal to facilitate safe and efficient early oral feeding [31], this is thought to improve in a linear fashion as they approach term equivalent age [18]. The current study documented significantly higher rates of poor arousal as well as inability to maintain the appropriate state for oral feeding in the preterm group, compared with the full-term group. Prior work has found that more time spent in a quiet alert state increases oral feeding efficiency [31], and 
Table 3 Feeding performance differences in preterm and full-term infants.

\begin{tabular}{|c|c|c|c|c|}
\hline & \multicolumn{3}{|c|}{ Mean $\pm \mathrm{SD}$ or $N(\%)$} & \multirow[t]{2}{*}{${ }^{*} p$ value } \\
\hline & $\begin{array}{l}\text { Total sample } \\
(n=92)\end{array}$ & $\begin{array}{l}\text { Preterm } \\
(n=44)\end{array}$ & $\begin{array}{l}\text { Full-term } \\
(n=48)\end{array}$ & \\
\hline PMA at time of feeding assessment & $38.4 \pm 1.9$ & $38.1 \pm 2.6$ & $38.7 \pm 1.0$ & 0.17 \\
\hline Infants bottle-fed during the assessment & $66(72 \%)$ & $43(98 \%)$ & $23(50 \%)$ & $<0.001$ \\
\hline \multicolumn{5}{|l|}{ Neonatal eating outcome scores } \\
\hline Total feeding assessment score & $75.3 \pm 13.2$ & $67.8 \pm 13.6$ & $82.2 \pm 8.1$ & $<0.001$ \\
\hline Categorical score & & & & $<0.001$ \\
\hline Normal & $48(52 \%)$ & $11(25 \%)$ & $37(77 \%)$ & \\
\hline Questionable & $32(35 \%)$ & $22(50 \%)$ & $10(21 \%)$ & \\
\hline Feeding challenged & $12(13 \%)$ & $11(25 \%)$ & $1(2 \%)$ & \\
\hline \multicolumn{5}{|l|}{ Prefeeding } \\
\hline Poor arousal & $19(21 \%)$ & $5(11 \%)$ & $14(29 \%)$ & $\mathbf{0 . 0 3}$ \\
\hline Poor rooting and grasp & $21(23 \%)$ & $13(30 \%)$ & $8(17 \%)$ & 0.14 \\
\hline Lack of sucking initiation & $28(30 \%)$ & $15(34 \%)$ & $13(27 \%)$ & 0.47 \\
\hline Poor tongue positioning & $19(6 \%)$ & $13(30 \%)$ & $6(13 \%)$ & 0.04 \\
\hline \multicolumn{5}{|l|}{ Oral feeding skills } \\
\hline Suck-swallow-breathe discoordination & $39(42 \%)$ & $38(86 \%)$ & $1(2 \%)$ & $<0.001$ \\
\hline Inadequate sucking bursts & $28(30 \%)$ & $19(43 \%)$ & $9(19 \%)$ & 0.01 \\
\hline Inadequate suction & $12(13 \%)$ & $8(18 \%)$ & $4(8 \%)$ & 0.01 \\
\hline Tonal abnormalities & $24(26 \%)$ & $19(43 \%)$ & $5(10 \%)$ & $<0.001$ \\
\hline $\begin{array}{l}\text { Discoordination of jaw and tongue during } \\
\text { sucking }\end{array}$ & $69(75 \%)$ & $41(93 \%)$ & $28(58 \%)$ & $<0.001$ \\
\hline $\begin{array}{l}\text { Lack of positive engagement or } \\
\text { discomfort }\end{array}$ & $50(54 \%)$ & $37(84 \%)$ & $13(27 \%)$ & $<0.001$ \\
\hline Moderate to severe fluid loss & $9(10 \%)$ & $7(16 \%)$ & $2(4 \%)$ & 0.058 \\
\hline Signs of aspiration & $35(38 \%)$ & $2761 \%)$ & $8(17 \%)$ & $<0.001$ \\
\hline Difficulty regulating breathing & $44(48 \%)$ & $39(89 \%)$ & $5(10 \%)$ & $<0.001$ \\
\hline \multicolumn{5}{|l|}{ Observation at the end of feeding } \\
\hline Inability to complete feeding & $28(30 \%)$ & $28(64 \%)$ & $0(0 \%)$ & $<0.001$ \\
\hline Inability to maintain an appropriate state & $20(22 \%)$ & $17(39 \%)$ & $3(6 \%)$ & $<0.001$ \\
\hline
\end{tabular}

PMA postmenstrual age.

Variables that were different across groups $(p<0.05)$ are bolded.

${ }^{*} p$ value is from investigating differences in preterm infants and full-term infants using independent samples $t$-tests for continuous variables and chi-square analyses and Fisher's Exact Test for categorical variables.

the quiet alert state is the most optimal state for infant engagement and safety during feeding [18]. Lower arousal in the preterm group can decrease successful oral feeding. These factors could have impacted our results, as many of preterm infant feedings were stopped due to low arousal and physiologic instability.

Preterm infants in our study were more likely to demonstrate suck-swallow-breathe discoordination, compared with their full-term counterparts. Suck-swallowbreathe discoordination can often appear as repetitive sequences of sucking and swallowing without adequate pauses for respiration [9]. The feeder can assist the infant by providing imposed breaks for respiration through external pacing methods [32]. Coordination of the suck-swallow-breathe pattern has been shown to improve with maturation [19, 20, 33, 34]. There were no significant differences in PMA at the time of assessment among the preterm and full-term infants, yet differences in the coordination of the suck-swallow-breathe pattern were evident. These findings are consistent with previous studies that have identified that lower EGA at birth and greater medical complexity can contribute to suck-swallow-breathe coordination difficulties in infants born preterm [14, 18, 35]. Our findings also support previous research that has identified that suck-swallow-breathe discoordination in preterm infants can be seen at term equivalent age [14].

Tonal abnormalities in preterm infants at term equivalent age were also observed in the current study. When oral tone 
of the preterm infant is insufficient, the infant may not be able to generate adequate pressure and suction needed to extract milk from the nipple; conversely if oral tone is too high, too much compression of the nipple may limit the efficiency at which milk is expressed and lead to diminished endurance and stamina $[20,36]$. Our findings are consistent with a previous study that identified low oral motor tone in preterm infants [15]. The tonal alterations observed in preterm infants could have been a contributing factor to observing a flat position of the tongue in the mouth with limited tongue cupping during feeding, as maintaining positioning of the tongue relies on adequate tone [37]. Although others have identified a decrease in compressive forces of the tongue during nutritive sucking among preterm infants $[15,20]$, we were not able to isolate this difference in the current study. However, these other studies used technologies that allowed precision in quantification, whereas the current study relied on a standardized assessment of feeding through observation.

Poor arousal, tone abnormalities, and suck-swallowbreathe discoordination in preterm infants could have contributed to observed discoordination of the jaw and tongue during sucking, moderate to severe fluid loss, difficulty regulating breathing, signs of aspiration, and lack of positive engagement and/or discomfort during oral feeding. Our study supports other research that has demonstrated that preterm infants have a higher risk of aspiration and physiologic instability during feeding [13, 38]. Our findings are also consistent with other work that has demonstrated fewer sucks per burst and discoordination of the jaw and tongue during sucking [21].

The period prior to and at term equivalent age is a rapid period of brain development [39], where experiences drive functional connections and relationships between brain regions [32]. While our study did not assess previous early feeding experiences, it is possible that early negative experiences may be related to the high prevalence of limited engagement in oral feeding and active avoidance. These negative experiences have been shown to lead to higher rates of aversive feeding behaviors and other oral feeding alterations that are prevalent in this population later in infancy and early childhood [1, 40]. Definitions of oral feeding success vary, but largely relate to intake of an appropriate volume without physiological instability [41]. However, the current study elucidates the significant feeding challenges that continue to exist among preterm infants at term equivalent age, even when feeding success can be claimed.

While oral feeding is often the last milestone needed in order for preterm infants to be discharged from the NICU [2], careful attention must be paid to the feeding process during the delicate neonatal period. Neonatal therapists (largely occupational therapists and speech-language pathologists) can provide assessment and intervention to optimize the early feeding process and drive positive feeding experiences into childhood [42, 43]. While successful oral feeding may be the goal, a focus on quality and positive feeding experiences, especially in the midst of feeding impairment, are important and can be guided by these early therapies.

\section{Study limitations}

This study had its limitations. This study was limited by significant variability in the medical courses of the preterm cohort, along with the timing that the feeding assessment occurred (between 35 and 43 weeks PMA for the preterm group and within 4 days of life for the full-term group). Preterm infants were assessed as close to NICU discharge as possible, but this was as early as 35 weeks PMA in some infants. The preterm group was evaluated during a period of rapid change in feeding skills, which could have introduced variability in performance. While there were no significant differences in the PMA at the time of testing among the preterm and full-term group, it is unclear if the findings would have been different if the preterm group was assessed at a different time period. Likewise, the time period in the hospital after full-term delivery is a period of transition, and feeding performance may or may not have evolved in the days or weeks following the assessment in the full-term group. There were more infants who were breastfed during the assessment in the full-term cohort, and it remains unclear if overall feeding performance could have been better or worse based on whether the infant was breast or bottle-fed. Feeding assessment was limited to one time frame, and this feeding assessment may or may not have been representative of the infant's general feeding performance. The feeding assessment also could have been impacted by other factors including the feeder, other activities that occurred during the day, hunger, or environmental factors. This study also relied on multiple comparisons, which increases the risk of a Type I error. The sample was derived from studies aimed at exploring early feeding performance, but the current study did not undergo prior power analysis. Despite these limitations, this is the first study, that we know of, to analyze the multiple components of feeding skill performance in preterm infants at term equivalent age compared with fullterm infants. The findings aid our understanding of early differences in feeding performance and set the stage for further inquiry.

Feeding is a complex task that requires the integration and organization of many skills. Our findings support that although oral feeding may be achieved, preterm infants continue to experience feeding performance alterations at term equivalent age. Isolating these differences can lead to 
individualized, targeted interventions to optimize early feeding experiences and improve outcomes.

Acknowledgements This work was supported by NIH (R24 HD065688/HD/NICHD) awarded by the Boston Rehabilitation Outcomes Center and by the Eunice Kennedy Shriver National Institute of Child Health and Human Development (U54 HD087011) to the Intellectual and Developmental Disabilities Research Center at Washington University. We would like to sincerely thank all the families and infants who participated in this research.

Disclosure The Neonatal Eating Outcomes Assessment copyright is currently owned by the Office of Technology Management at Washington University in St. Louis. This tool can be accessed by the public through licensing. While currently available "at cost," there could be potential profit to Washington University in St. Louis in the future.

Author contributions RP was involved with concept/design, developing methodology and supervising the investigation, providing oversight, achieving funding, writing the initial draft of the manuscript, as well as editing and approving the final version of the manuscript submitted. DP was involved with data acquisition and management, conducting analyses, writing the initial draft of the manuscript, and editing and approving the final draft for submission. JR was involved with oversight regarding intellectual content as well as reviewing, editing, and approving the final version of the manuscript submitted. MG was involved with data acquisition and management, formal analyses, as well as reviewing, editing, and approving the final version of the manuscript submitted. JS was involved with conducting the investigation, oversight of methodology, as well as reviewing, editing, and approving the final version of the manuscript submitted.

\section{Compliance with ethical standards}

Conflict of interest RP is the author of the Neonatal Eating Outcome Assessment. The other authors declare that they have no conflict of interest.

Publisher's note Springer Nature remains neutral with regard to jurisdictional claims in published maps and institutional affiliations.

\section{References}

1. Lau C. Development of infant oral feeding skills: what do we know? Am J Clin Nutr. 2016;103:616-21.

2. Merritt TA, Pillers D, Prows SL. Early NICU discharge of very low birth weight infants: a critical review and analysis. Semin Neonatol. 2003;8:95-115.

3. Lau C. Development of oral feeding skills in the preterm infant. Arch Pediatr. 2007;14:35-41.

4. Lau C. Development of suck and swallow mechanisms in infants. Ann Nutr Metab. 2015;66:7-14.

5. Herbst JJ. Development of suck and swallow. J Pediatr Gastroenterol Nutr. 1983;2:131-5.

6. Burklow KA, McGrath AM, Valerius KS, Rudolph C. Relationship between feeding difficulties, medical complexity, and gestational age. Nutr Clin Pract. 2002;17:373-8.

7. Barkat-Masih M, Saha C, Hamby DK, Ofner S, Golomb MR. Feeding problems in children with neonatal arterial ischemic stroke. J Child Neurol. 2010;25:867-72.
8. Quattrocchi CC, Longo D, Delfino LN, Cilio MR, Piersigilli F, Capua MD, et al. Dorsal brain stem syndrome: MR imaging location of brain stem tegmental lesions in neonates with oral motor dysfunction. Am J Neuroradiol. 2010;31: 1438-42.

9. Ludwig SM. Oral feeding and the late preterm infant. Newborn Infant Nurs Rev. 2007;7:72-5.

10. Howe T-H, Sheu C-F, Hinojosa J, Lin J, Holzman IR. Multiple factors related to bottle-feeding performance in preterm infants. Nurs Res. 2007;56:307-11.

11. Jadcherla SR, Wang M, Vijayapal AS, Leuthner SR. Impact of prematurity and co-morbidities on feeding milestones in neonates: a retrospective study. J Perinatol. 2010;30:201-8.

12. McGrath JM, Braescu AV. State of the science: feeding readiness in the preterm infant. J Perinat Neonatal Nurs. 2004;18:353-68.

13. Davis NL, Liu A, Rhein L. Feeding immaturity in preterm neonates: risk factors for oropharyngeal aspiration and timing of maturation. J Pediatr Gastroenterol Nutr. 2013;57:735-40.

14. da Costa SP, van der Schans CP, Zweens MJ, Boelema SR, van der Meij E, Boerman MA, et al. The development of sucking patterns in preterm, small-for-gestational age infants. J Pediatr. 2010;157:603-9.

15. Capilouto GJ, Cunningham T, Frederick E, Dupont-Versteegden E, Desai N, Butterfield TA. Comparison of tongue muscle characteristics of preterm and full term infants during nutritive and nonnutritive sucking. Infant Behav Dev. 2014;37:435-45.

16. Gardner SL, Hagedorn MI. Physiologic sequelae of prematurity: the nurse practitioner's role. Part V. Feeding difficulties and growth failure (Pathophysiology, cause, and data collection). J Pediatr Health Care. 1991;5:122-34.

17. Chandrasekharan P, Rawat M, Reynolds AM, Phillips K, Lakshminrusimha S. Apnea, bradycardia and desaturation spells in premature infants: impact of a protocol for the duration of 'spell-free' observation on interprovider variability and readmission rates. J Perinatol. 2018;38:86-91.

18. Pickler RH, Best AM, Reyna BA, Wetzel PA, Gutcher GR. Prediction of feeding performance in preterm infants. Newborn Infant Nurs Rev. 2005;5:116-23.

19. Bu'Lock F, Woolridge MW, Baum JD. Development of coordination of sucking, swallowing and breathing: ultrasound study of term and preterm infants. Dev Med Child Neurol. 1990; 32:669-78.

20. Medoff-Cooper B, McGrath JM, Shults J. Feeding patterns of fullterm and preterm infants at forty weeks postconceptional age. J Dev Behav Pediatr. 2002;23:231-6.

21. Capilouto GJ, Cunningham TJ, Giannone PJ, Grider D. A comparison of the nutritive sucking performance of full term and preterm neonates at hospital discharge: a prospective study. Early Hum Dev. 2019;134:26-30.

22. Pineda R, Harris R, Foci F, Roussin J, Wallendorf M. Neonatal eating outcome assessment: tool development and inter-rater reliability. Acta Paediatr. 2018;107:414-24.

23. Pineda R. Neonatal eating outcome assessment manual and scoresheet. 2017. https://commerce.cashnet.com/cashnetg/selfserve/Brow seCatalog.aspx.

24. Pineda R, Liszka L, Kwon J, Wallendorf M. Inter-rater reliability and concurrent validity of the neonatal eating outcome assessment. Am J Occup Ther. 2020;74.

25. Motion S, Northstone K, Emond A, Team TAS. Persistent early feeding difficulties and subsequent growth and developmental outcomes. Ambul Child Health. 2001;7:231-7.

26. Hawdon JM, Beauregard N, Slattery J, Kennedy G. Identification of neonates at risk of developing feeding problems in infancy. Dev Med Child Neurol. 2000;42:235-9.

27. Hoogewerf M, Ter Horst HJ, Groen H, Nieuwenhuis T, Bos AF, van Dijk MWG. The prevalence of feeding problems in children 
formerly treated in a neonatal intensive care unit. J Perinatol. 2017;37:578-84.

28. Pineda RG, Tjoeng TH, Vavasseur C, Kidokoro H, Neil JJ, Inder T. Patterns of altered neurobehavior in preterm infants witin the neonatal intensive care unit. J Pediatr. 2013;162:470-476.e1.

29. de Souza Perrella VV, de Moraes BMC, Sañudo A, Guinsburg R. Neurobehavior of preterm infants from 32 to 48 weeks postmenstrual age. J Perinatol. 2019;39:800-7.

30. Ludwig SM, Waitzman KA. Changing feeding documentation to reflect infant-driven feeding practice. Newborn Infant Nurs Rev. 2007;7:155-60.

31. Griffith T, Rankin K, White-Traut R. The relationship between behavioral states and oral feeding efficiency in preterm infants. Adv Neonatal Care. 2017;17:12-9.

32. Ross ES, Philbin MK. Supporting oral feeding in fragile infants: an evidence-based method for quality bottle-feedings of preterm, ill, and fragile infants. J Perinat Neonatal Nurs. 2011;25:349-57.

33. Medoff-Cooper B, Verklan T, Carlson S. The development of sucking patterns and physiologic correlates in very-low-birthweight infants. Nurs Res. 1993;42:100-5.

34. Sakalidis VS, Kent JC, Garbin CP, Hepworth AR, Hartmann PE, Geddes DT. Longitudinal changes in suck-swallow-breathe, oxygen saturation, and heart rate patterns in term breastfeeding infants. J Hum Lact. 2013;29:236-45.

35. Maastrup R, Hansen BM, Kronborg H, Bojesen SN, Hallum K, Frandsen A. et al. Breastfeeding progression in preterm infants is influenced by factors in infants, mothers and clinical practice: the results of a national cohort study with high breastfeeding initiation rates. PloS One. 2014;9:e108208.

36. Einarsson-Backes LM, Deitz J, Price R, Glass R, Hays R. The effect of oral support on sucking efficiency in preterm infants. Am J Occup Ther. 1994;48:490-8.

37. Da Costa SP, van Den Engel-Hoek L, Bos AF. Sucking and swallowing in infants and diagnostic tools. J Perinatol. 2008;28:247-57.

38. Barlow SM. Oral and respiratory control for preterm feeding. Curr Opin Otolaryngol Head Neck Surg. 2009;17:179-86.

39. Konkel L. The brain before birth: ssing fMRI to explore the secrets of fetal neurodevelopment. Environ Health Perspect. 2018; 126:112001.

40. Palmer MM. Identification and management of the transitional suck pattern in premature infants. J Perinat Neonatal Nurs. 1993;7:66-75.

41. Griffith TT, Bell AF, Vincent C, White-Traut R, Medoff-Cooper B, Rankin K. Oral feeding success: a concept analysis. Adv Neonatal Care. 2019;19:21-31.

42. Ross K, Heiny E, Conner S, Spener P, Pineda R. Occupational therapy, physical therapy and speech-language pathology in the neonatal intensive care unit: patterns of therapy usage in a level IV NICU. Res Dev Disabil. 2017;64:108-17.

43. Goldstein RF, Malcolm WF. Care of the neonatal intensive care unit graduate after discharge. Pediatr Clin North Am. 2019;66: 489-508. 